writing or any work requiring delicate manipulation; slight vertigo; profound depression without adequate cause, occasionally succeeded by inappropriate outbursts of merriment; nervousness and a love of solitude, yet accompanied by a dread of being alone; a general feeling of malaise which cannot be accounted for, succeeded, if the disease be not checked, by the comfortable sensations accompanying general paralysis in its more advanced stages.

As we have said, it is impossible to foretell the exact form the nervous disorder will take. Obviously the treatment of such symptoms is prophylactic rather than medical. The patient should avoid all that is evil and do all that is good. He should seek society quietly.and in moderation, avoiding heavy dinners, late hours, and alcoholic excess. He should take regular outdoor exercise, but not enough to fatigue. Any new game, such as lawn-tennis, in one who has not played before, is to be deprecated. Even a revival of the sports of youth after a long cessation from them has its risks. He should sleep enough and not too much, being careful not to make any too sudden alteration in this respect. Sexual intercourse should be altogether avoided while the abovementioned symptoms are present. In married people, an abstinence for three months in mild cases, and for six months in those which are more severe, are the shortest periods from which any good can be expected. The smaller picture-galleries or open-air sports should be preferred as amusements to stifling theatres and prolonged concerts. The patient should do less work than usual, and, if possible, throw his worries into the hands of a trustworthy agent. All absorbing accomplishments, all arduous reading, should be put aside for a time, and novels of the lightest and least exciting description should be indulged in. A course of "Pickwick" is invaluable in such cases. The patient should avoid all sources of irritation, and should remember that, if he, as the head of the house, has his troubles to bear, there may be others who are compelled to live with him, who, like the Spartan boy, are gnawed within by a wolfish sorrow. But in any case, should any group of the symptoms enumerated arise, the family physician should be consulted, as it is impossible for those who hare not studied medicine to compete, in treating eren their own cases, with those who have been born and bred in the art of healing.

Richmond-terrace, S.W.

\section{REMOVAL OF THE TONGUE AND FLOOP OF THE MOUTH FOR EXTENSIVE EPITHELIOMA.}

By MAYO COLLIER, M.S. LoND., F.R.C.S. ENG.,

SENTOR ASSTSTANT-SURGEON TO THE NORTH-WEST LOXDOX HOSPITAL, ASSISTANT DEMONSTRATOR OF AXATOMY AT THE LONDOY HOSPITAL IIEDICAL COLIEGE.

THREs weeks ago I was consulted by a patient, aged sixty-nine, suffering from an affection of the tongue and floor of the mouth. He had first noticed a sore three months ago near the right border of the tongue about its middle. The disease had quickly spread, and involved the anterior two-thirds of the tongue and floor of the mouth symmetrically, rendering the organ immovable, and completely filling the floor of the mouth. The patient had been a great smoker, was possessed apparently of good teeth, but suffered considerable pain in the right side of the jaw and face. He stated he was getting weak and losing flesh. There was no family history of cancer.

There was no doubt that this was a case of extensive epithelioma, and the only points in reserve were the advisability and practicability of its removal. Having consulted with Sir W. Mac Cormac, I determined to remove the whole growth from below, feeling sure it could be done. The case was sent into St. Thomas's Home, and on Friday, the 19th, I performed the following operation, being kindly assisted by Mr. Battle, Mr. Jennings, and Mr. Sanderson.

The two lingual arteries were first secured by ligatures at the apices of the great cornua of the hyoid bone, so as to prevent subsequent bleeding from the dorsalis lingual, sublingual, and ranine arteries. The ordinary curved skin incisions from the angle of the jaw to the chin were adopted, the centre of the curve just reaching the attachment of the tendon of the digastric muscle to the hyoid bone. The vil. maxillary glands were next turned outwards and the fro edges of the mylo-hyoid muscles exposed. These tif notched as far as the outer borders of the genio-hrid muscles, thus preserving the central attachments, "Th under aspect of the floor of the mouth was now perfecti free, and one finger being passed between the genis. hyo-glossi and genio-hyoid muscles, as a guide, the tongu and floor of the mouth were completely and easily separatt. from the lower jaw. $\Lambda$ further separation was effected as tal down as the hyoid bone, and the whole structures-tongite sublingual glands, and floor of mouth-remored en masse bi the écraseur. Not the slightest hæmorrhage followed the removal. The inner aspect of the jaw was next scraped, and some affected glands discovered at the outer borders of the genio-hyoid muscles being removed, the cavity was swablet out with a solution of chloride of zinc (forty grains to ounce). Two large drainage-tubes were secured on each side of the stump, and brought out below the angle of th jaw, so as to ensure perfect drainage by occupying the most dependent positions. The wounds in the neck were closed by silk sutures, and dressed with dry iodoform wool ant gauze.

During the operation, which lasted a little orer an hows, not the slightest difficulty was experienced by the and thetist, neither did blood enter the larynx or pharyn At no time had the anæsthetic to be discontinued, the breathing being good throughout. The subsequent progress of the case has been all that could be clesired. By the us of iodoform and good drainage the breath has remained perfectly sweet. Fo discharge has reached the laryn o? pharynx, and the temperature has scarcely been abore normal. The stitches were removed on the third day. Fhen I last visited the patient he was sleeping tranquilly, and was reported to have taken nourishment freely, slept well. and complained of nothing.

Aug. 18th.--The patient progressed most satisfactorily, and ieft the Home on the twenty-first day. He has regained strength and improved in weight, and has just risited me having walked three miles. There is not the slightest ap. pearance of return, and the patient experiences no diffentity in swallowing or in making himself intelligible.

Remarlis.-An attempt to remove the growth by the mouth was out of the question, and, as section of the lip an lower jaw does not offer any great advantages, I resorted to the method related, feeling certain that this is the easiest and safest operation in all difficult cases. Czerny he derised an exactly similar operation, but with what success I am unable to say. Now, I claim for this mode a procedure advantages that are many and manifest:1. There is no danger at any time of the patient being suffocated by his own blood, and so no necessity for tracheotomy before, during, or after the operation, the tongue and floor of the mouth being the last structure divided. 2. There is no interference with the ande thetist till the last few moments, when the structure are divided en masse, thus dispensing with disagreesble pauses in the operation and partial return to conscioliness of the patient. 3. There is no danger of the stum falling back on the larynx, as the attachments of the laryin and liyoid bone to the lower jaw are preserved. 4. The whole growth, however extensive, with any diseased glands can be entirely removed. 5. Perfect drainage of the earitr is obtained by placing the drainage-tubes in the most dependent positions, so ensuring against sepsis, preventing any overflow into the larynx, and allowing the patient sleep comfortably in the recumbent position. 6. The opetation is almost bloodless if proper care be taken.

New Cavendish-street, $W$.

Hospital Saturday Fund.-At a recent meeting the Council of this fund attention was called to the action of the managing authorities of University College Hospital in limiting the nurses of the establishment to members the Church of England, and refusing to receive as a jot bationer nurse a Tonconformist lady. Much discusing ensued; but as the anvards of the fund, based upon th utility achieved, efficiency of management attained, act economy practised in the participating institutions, rere undetermined for the present year, it was decided to refer the Distribution Committee all the circumstances conneted with the present controversy which have arisen as to losping nursing. 